\title{
PEMBUATAN ANIMASI 3D SOSIALISASI PENGGUNAAN JALUR SIMPANGAN DAN BUNDARAN KETIKA BERKENDARA
}

\author{
Maya Marselia* \\ Cita Meysiana \\ Politeknik Negeri Sambas
}

\begin{abstract}
This research aimed to make a 3D animated video used to provide information about the ethics of driving at intersections and roundabouts according to the rules that apply to the public or vehicle users to reduce traffic accidents. This research uses the MDLC (Multimedia Development Life Cycle) method. Making this 3D animated video consists of several stages, starting from the initial stage, namely determining the idea, the data collection stage, the storyboard design, modeling process, texturing, rigging, animating, and rendering using the blender and make human applications. After the rendering process is complete, the next stage is editing by providing text, image, transitions effects using the Adobe Premiere Pro applications and adding audio as the voice-over to the story script. The last stage is the final rendering process. This research produces a 3-dimensional animated video socializing driving ethics by focusing on intersections and roundabouts with a duration of 7 minutes 47 seconds, with an MP4 file format and a file size of $691 \mathrm{MB}$.
\end{abstract}

Keywords:

$3 D$ animation, Blender, socialization video

\begin{abstract}
Abstrak
Tujuan dari penelitian ini adalah pembuatan video animasi 3D yang digunakan untuk memberikan informasi tentang etika berkendara di simpangan dan bundaran sesuai dengan aturan yang berlaku bagi masyarakat atau pengguna kendaraan, agar dapat mengurangi tingkat kecelakaan pada lalu lintas. Penelitian ini penggunakan metode MDLC (Multimedia Development Life Cycle) dan dalam pembuatan video animasi 3D terdiri dari beberap tahap yaitu dimulai dari tahap awal yaitu penentuan ide, tahap pengumpulan data, hingga perancangan storyboard, proses modelling, texturing, rigging animating, dan rendering menggunakan aplikasi Blender dan Makehuman. Setelah proses rendering selesai, tahap selanjutnya adalah final editing dengan memberikan teks, gambar, efek transisi menggunakaan aplikasi Adobe Premiere Pro serta menambahkan audio sebagai pengisi suara pada naskah cerita. Tahap terakhir adalah proses final rendering. Penelitian ini menghasilkan video animasi 3 dimensi sosialisasi etika berkendara berkendara dengan berfokus pada jalur simpangan dan bundaran berdurasi 7 menit 47 detik, dengan format file MP4 dan berukuran file $691 \mathrm{MB}$.
\end{abstract}

Kata Kunci:

Animasi 3D, Blender, video sosialisasi.

DOI: $10.38038 /$ vocatech.v2i2.55

Received: 15 February 2021 ; Accepted: 30 March 2021 ; Published: 20 April 2021

\section{*Corresponding author:}

Maya Marselia, Program Studi Teknik Multimedia, Politeknik Negeri Sambas, Jl. Raya Sejangkung Kawasan Pendidikan Tinggi Sambas, Tumuk Manggis, Kec. Sambas, Kabupaten Sambas, Kalimantan Barat 79463, Indonesia Email: maya.marselia89@gmail.com

Citation in APA Style: Marselia, M., \& Meysiana, C. (2021). Pembuatan Animasi 3D Sosialisasi Penggunaan Jalur Simpangan dan Bundaran Ketika Berkendara. VOCATECH: Vocational Education and Technology Journal, Vol. 2, 2 (2021), 104-112. 


\section{PENDAHULUAN}

Salah satu teknologi yang memberikan informasi dan sangat marak sekali digunakan khalayak umum adalah teknologi multimedia dibidang animasi 2 dimensi dan animasi 3 dimensi. Pada perkembangan teknologi saat ini video yang paling tepat untuk penyampaian informasi secara lugas (Marselia et al., 2017). Sajian sosialisasi pasti akan menarik dan lebih mudah diakses. Sosialisasi jadi lebih menarik dan masyarakat mudah menyerap informasi yang akan disampaikan. Penonton pun tidak bosan dengan materi sosialisasi (Anin, 2020).

Penyampaian informasi yang menggunakan teknologi multimedia salah satunya adalah sosialisasi tata cara berkendara. Pada perkembangan zaman saat ini pengguna kendaraan sangat meningkat dan tingkat kecelakaan pun semakin meningkat. Dari beberapa hasil penelitian menjelaskan bahwa sering terjadi keramaian di jalan dengan pola-pola tertentu, bisa dilihat pada pagi hari masyarakat berangkat kerja maupun berangkat ke sekolah, kemudian pada waktu siang yang memungkinkan jalanan sedikit lenggang, serta pada sore hari yang jalanan mulai dipadati oleh masyarakat yang pulang kerja, pelajar yang pulang sekolah, yang dimana hal tersebut dapat mengakibatkan antrian panjang di jalanan. Dari catatan Satuan Lalu Lintas POLRES Sambas faktor penyebab kecelakaan adalah manusia (human error), kendaraan dan lingkungan. Namun $80 \%$ penyebab kecelakaan lalu lintas adalah manusia (human error). Faktor perilaku pengemudi salah satunya adalah tidak memiliki pengetahuan dan etika sopan santun berlalu lintas, utamanya dalam tata cara mendahului kendaraan, penggunaan jalur simpangan dan bundaran, maupun tata cara keluar masuk gang atau jalan (Nalendra et al., 2020) (Lu et al., 2017). Untuk di Kabupaten Sambas berdasarkan data kejadian laka yang tercatat di Satuan Lalu Lintas POLRES Sambas pada tahun 2019 dari periode Januari sampai Desember total keseluruhan sebanyak 75 kasus, dengan korban meninggal dunia 47 orang, luka berat 48 orang, luka ringan 72 orang dan kerugian materil Rp. 234.900.000. Pada tahun 2020 dari periode Januari sampai Juni total keseluruhan kecelakaan terdapat 43 kasus, dengan korban meninggal dunia 31 orang, luka berat 19 orang, luka ringan 37 orang dan kerugian materiil
Rp. 110.050.000 berdasarkan Laporan Tahunan LAKA LANTAS POLRES Sambas tahun 2020.

Untuk mempermudah proses sosialisasi etika berkendara maka diperlukan bentuk komunikasi yang lebih atraktif dan menarik dalam bentuk video animasi 3 dimensi. Sosialisasi dalam bentuk video animasi 3D mempunyai banyak kelebihan yaitu: (a) dipahami dengan mudah, dan lebih mudah diterima penonton. (b) sesuatu yang sulit diilustrasikan dan tidak bisa dijangkau dapat dibuat dalam bentuk animasi (c) Animasi dapat membuat ketertarikan pengiklanan animasi dikarenakan bisa membangun visualisasi yang hampir sama dengan aslinya (d) lebih menghemat biaya dari pada pembuatan non animasi, dikarenakan proses pembuatan animasi tidak sama dengan pembuatan informasi biasa (Candra, 2017). Diharapkan dengan pembuatan video animasi 3D ini masyarakat ataupun pengguna kendaraan dapat menerapkan informasi yang diberikan, agar dapat mengurangi tingkat kecelakaan dalam berkendara. Dengan dibuatnya video animasi 3D ini diharapkan mampu memudahkan dalam proses penerapan aturan dalam berlalu lintas serta dengan adanya bantuan video animasi 3D ini akan menyajikan informasi dalam waktu yang lebih singkat dan memberikan informasi yang kuat.

\section{STUDI PUSTAKA}

Ditahun 1981 Prinsip-prinsip animasi dibuat oleh animator Profesional di Studio Walt Disney yaitu Ollie Johnston dan Frank Thomas pada bukunya yang berjudul The Illusion of Life: Disney Animation. Terdapat 12 prinsip yang digunakan untuk diskusi kreatif dan membantu produksi serta untuk memberi pelatihan kepada kaum muda dengan lebih baik (Ollie \& Thomas, 1981). 12 prinsip animasi tersebut yaitu : Solid Drawing, Timing \& Spacing, Squash \& Stretch, Anticipation, Slow In and Slow Out, Arcs, Secondary Action, Follow Through and Overlapping Action, Straight Ahead Action and Pose to Pose, Staging, Appeal, \& Exaggeration.

Animasi memiliki arti harfiah yaitu menghidupkan. Dimana usaha untuk menggerakkan suatu objek yang tadinya diam menjadi sesuatu yang dapat bergerak. Dalam definisi lain adalah sebuah karya seni yang digunakan untuk memanipulasi atau membuat 
gambar yang tadinya diam menjadi seolah-olah dapat bergerak. Perkembangan animasi saat ini semakit pesat, tidak hanya untuk hiburan namun animasi digunakan dalam media pembelajaran, media informasi, dan juga digunakan dalam Pendidikan (Priyoatmoko, 2017).

Animasi 3D adalah bentuk yang memiliki, lebar, panjang dan kedalaman serta mempunyai tiga dimensi. Pada animasi 3D dapat dimanipulasi menjadi objek yang dikehendaki dan dapat dipandang dari segala arah. Sehingga sangat mirip dengan dunia nyata maka dari itu dinamakan dengan kenyataan semu atau dunia maya (Darmawan et al., 2020).

Animasi 3D adalah objek yang memiliki tiga buah dimensi ukuran yaitu panjang, lebar, dan kedalaman. Kita dapat memanipulasi sebuah objek sekehendak hati dan dapat memandang sebuah objek dari segala arah. Konsep ini sangat mirip dengan dunia yang sebenarnya sehingga diberi nama dengan kenyataan semu atau dunia maya. Terdapat 3 tahap pembuatan animasi 3D, yaitu Moddelling, Animation, dan Rendering (Defar, 2019). Bentuk 3 dimensi ini yaitu bangunan dimana bangunan tersebut terdiri dari beberapa bidang di dalam ruang 3 dimensi, vertex, edge, face, dan texture disusun dari beberapa elemen dasar (Widiaty et al., 2018).

Obyek 3 dimensi adalah bangunan yang tersusun dari beberapa bidang dalam ruang 3 dimensi. Untuk membentuk suatu obyek 3 dimensi. terdapat beberapa elemen dasar yang menyusunnya yaitu vertex, edge, face, dan texture. Dalam komputer gratis 3 dimensi. Vertex yaitu struktur dasar dalam pembentukan obyek dan titik yang terdapat pada ruang 3 dimensi serta bagian terkecil di suatu bentuk 3 dimensi. Di dalam vertex terdapat informasi yang disimpan yaitu koordinat $\mathrm{x}, \mathrm{y}, \mathrm{z}$ dari titik tersebut. Dua vertex dapat ditarik garis yang disebut edge. Maka garis yang terdapat di ruang 3 dimensi disebut edge. Perbedaannya dengan vertex, informasi yang ada di dalam edge adalah edge yang dibentuk dari vertex awal dan vertex akhir. Face yaitu sebuah bidang yang terbentuk dari 3 vertex. Karena dibentuk dari tiga vertex dan berada di ruang 3 dimensi maka face berbentuk segitiga. Informasi yang ada di bagian face hampir sama dengan edge yaitu terbentuk dari tiga buah vertex (Rubil et al., 2013).

Simpul transportasi yang terbentuk dari beberapa pendekatan atau lengan yang dibentuk, tempat di mana arus kendaraan dari beberapa sumber bertemu dan berpencar menjauhi simpang. Simpang jalan adalah tempat yang biasanya sering terjadi kecelakaan karena terjadinya pertemuan antar kendaraan satu dengan kendaraan yang lain atau bisa saja dengan pejalan kaki (Hobbs, 2009).

Jika dikelompokkan ke dalam bentuk dan bahan yang digunakan maka jenis film atau video animasi ini termasuk film Animasi Boneka (Puppet Animation) karena objek yang digunakan dalam video animasi ini adalah objek boneka, dimana dilakukan penyederhanaan dari bentuk benda alam yang sudah tersedia. Bahan yang digunakan adalah plastik keras, kayu kemudian bahan keras yang disesuaikan dengan sifat karakter di dalam film animasi model bentuk animasi sederhana dan pemakaiannya juga tidak begitu rumit namun bukan berarti bahan lentur tidak dipakai. Salah satu film yang menggunakan teknik yang sederhana adalah Film Animasi Potongan (Cut - out Animation). Objek atau fitur yang akan dibuat dirancang terlebih dahulu kemudian digambar di atas kertas, kemudian dipotong sesuai dengan objek yang telah dibuat sebelumnya, dan diletakkan diatas bidang datar yang digunakan sebagai latar belakang. Kemudian pada Film Animasi Bayangan (Silhoutte Animation) merupakan jenis film animasi yang cara penggunaannya hampir sama, dimana menggunakan latar belakang yang terang dan bagian objek animasinya berupa bayangan karena pencahayaannya terdapat dibelakang layar objek. Kemudian ada juga film animasi yang memiliki teknik yang bebas mengembangkan keinginan sendiri untuk dapat menggerakkannya (Syahfitri, 2011).

Media audio visual merupakan wahana sebagai penyalur pesan dan informasi dalam belajar. Sedangkan media penyampaian informasi yang mempunyai karakteristik suara (audio) dan gambar (visual) disebut dengan media audiovisual. Jenis media audio-visual memiliki kemampuan yang lebih baik karena memiliki kedua karakteristik tersebut. Kemudian media audio-visual terdapat 2 bagian yaitu 1) Audiovisual gerak adalah media yang terdapat unsur gambar beserta suara yang bergerak seperti meliputi suara dan Video cassette, 2) Audio-visual diam meliputi bingkai suara (sound slide) dimana media yang ditampilkan berupa suara dan gambar diam (Haryoko, 2012). 


\section{METODE}

Metode konsep desain yang digunakan dalam penelitian ini adalah dengan metode permodelan primitif yang mana menggunakan objek yang ada pada mesh aplikasi blender seperti kubus, silinder, kerucut dan lain lain. Teknik modifikasi yang digunakan terdapat pada vertex, edge dan face.

Adapun konsep perancangan dalam penelitian ini dapat dilihat pada Gambar 1. flowchart konsep perancangan.

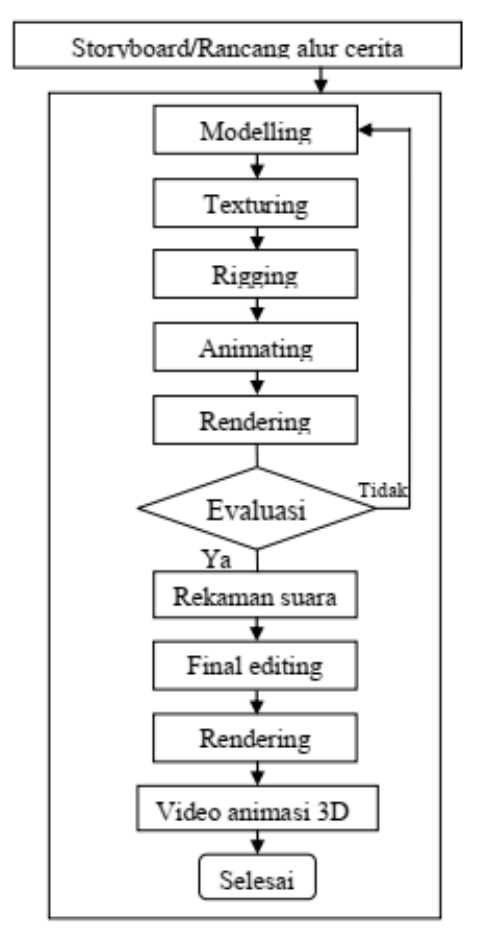

Gambar 1. Flowchart konsep perancangan

Analisis data adalah proses mengatur urutan data, mengorganisasikannya ke dalam pola, kategori, dan unit dasar deskripsi (Moleong, 2013). Analisa data juga dapat diartikan ke dalam upaya mencari dan menata secara sistematis catatan hasil observasi, wawancara dan lainnya untuk meningkatkan pemahaman penelitian tentang kasus yang diteliti dan menyajikan sebagai temuan bagi orang lain.

Pada metode pengembangan ini, penulis membuat media pembelajaran berbasis animasi menggunakan metode penelitian MDLC (Multimedia Development Life Cycle). Yaitu sebuah metode pengembangan rancang bangun perangkat lunak multimedia yang tahap-tahap metode MDLC ini adalah concept (pengonsepan), design (perancangan), material collecting (pengumpulan bahan), assembly (pembuatan), testing (pengujian), dan distribution (pendistribusian). Menurut Luther, tahap-tahap ini dapat berganti posisi jadi dalam mempraktekkannya tidak harus selalu berurutan. Namun pada tahap concept tetap menjadi hal yang pertama dalam pengerjaannya (Tamin, 2008). Berikut adalah gambar tahapan metode Multimedia Development Life Cycle MDLC.

Metode MDLC ini merupakan metode yang dikhususkan untuk pembuatan produk yang merupakan produk multimedia dimana tiap-tiap tahap di dalam metode ini memiliki sifat yang fleksibel contohnya ketika kita sudah berada di tahap assembly maka kita oleh kembali lagi kepada tahap material collecting maupun kepada tahap design dan konsep (Cahyadi et al., 2020). Berikut adalah gambar tahapan metode Multimedia Development Life Cycle MDLC.

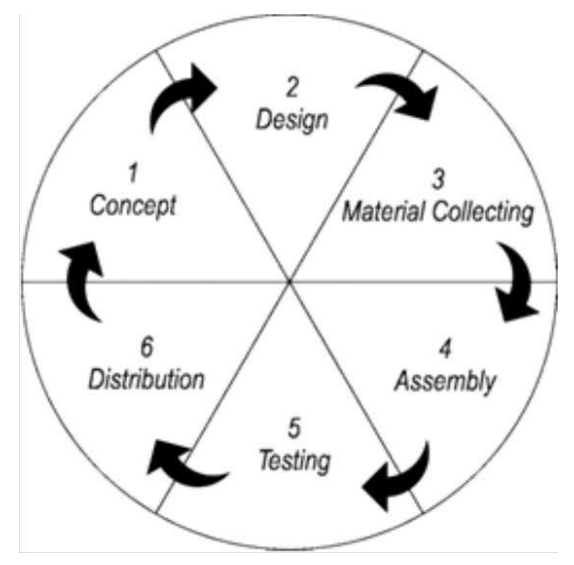

Gambar 2. Metode Multimedia Development Life Cycle MDLC

\section{HASIL DAN PEMBAHASAN}

\section{A. Pembahasan}

Banyak properti yang digunakan dalam pembuatan video animasi $3 \mathrm{D}$ tata cara berkendara meliputi: Rumput. Pembuatan rumput dilakukan pada aplikasi blender dengan menggunakan dua jenis rumput yang sudah tersedia pada aplikasi blender yaitu simple dan interpolated. Dari jumlah banyaknya, rumput untuk dua jenis ini sama yaitu 500 dan dengan panjang $0,280 \mathrm{~cm}$. 


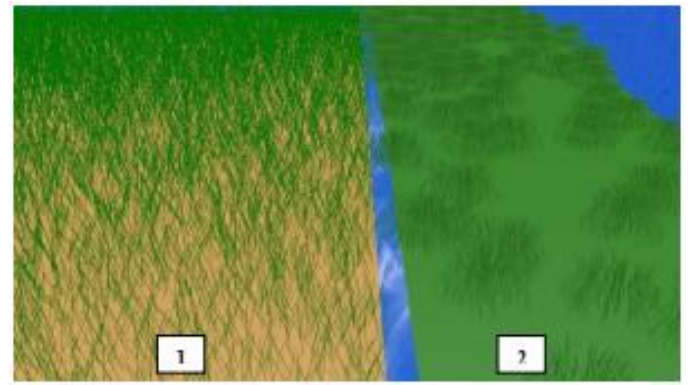

Gambar 3. Rumput Jenis 1. Simple dan 2. Interpolated

Pohon. Properti yang digunakan selanjutnya adalah pohon. Pembuatan pohon dilakukan pada aplikasi blender dengan jenis pohon yang telah disediakan pada aplikasi blender. Pada video animasi 3D ini properti pohon yang digunakan dengan ukuran sumbu $\mathrm{x}=12.425, \mathrm{y}=9512$, dan $\mathrm{z}=10.871$.

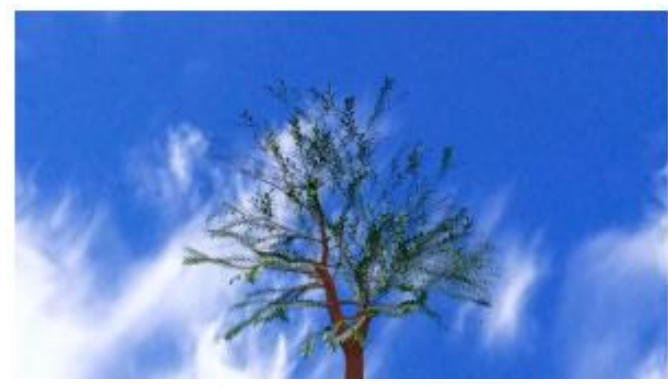

Gambar 4. Properti Pohon

Background awan. Untuk backgroud awan dimasukkan pada aplikasi blender dengan format gambar jpg. Jenis awan yang dipilih adalah cerah berawan karena video animasi 3D tata cara berkendara ini dibuat seolah-olah pada siang hari. Untuk memasukkan background awan pada aplikasi blender sudah tersedia di properties yaitu tekan $\mathrm{n} \rightarrow$ background images $\rightarrow$ add image $\rightarrow$ add new texture (dengan gambar yang sama).

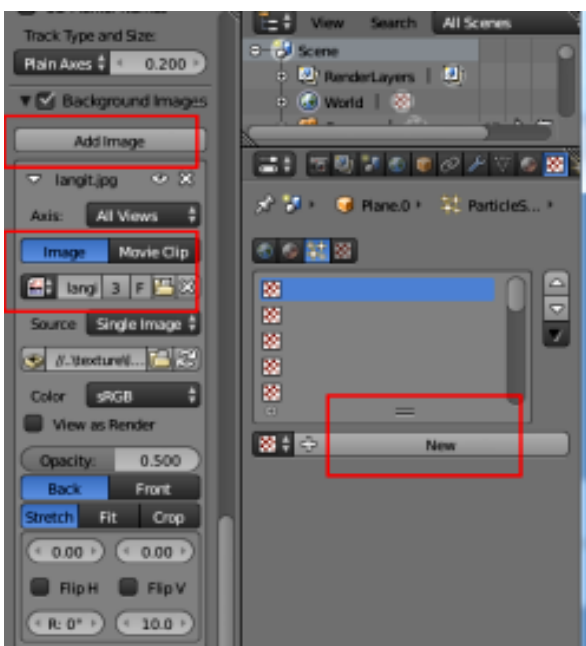

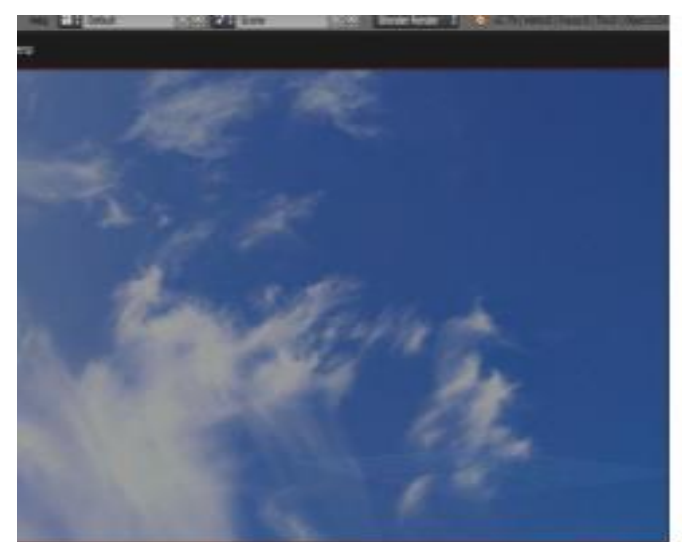

Gambar 5. Properti Background Pohon

Tiang Listrik. Pembuatan tiang listrik dilakukan pada aplikasi blender dengan objek dasar cylinder dan menggunakan teknik modelling extrude and scale. Ukuran dari tiang listrik adalah sumbu $\mathrm{x}=$ $0.500, \mathrm{y}=6.000$, dan $\mathrm{z}=12.844$.

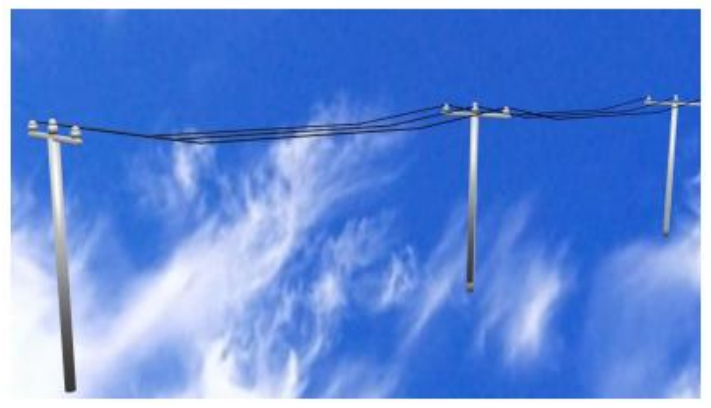

Gambar 6. Properti Background Pohon

Lampu Jalan. Pembuatan lampu jalan dilakukan pada aplikasi blender dengan objek dasar cylinder dan dengan teknik modeling extrude and scale. Ukuran dari lampu jalan adalah sumbu $\mathrm{x}=0.400$, $\mathrm{y}=0.594$, dan $\mathrm{z}=10.860$.

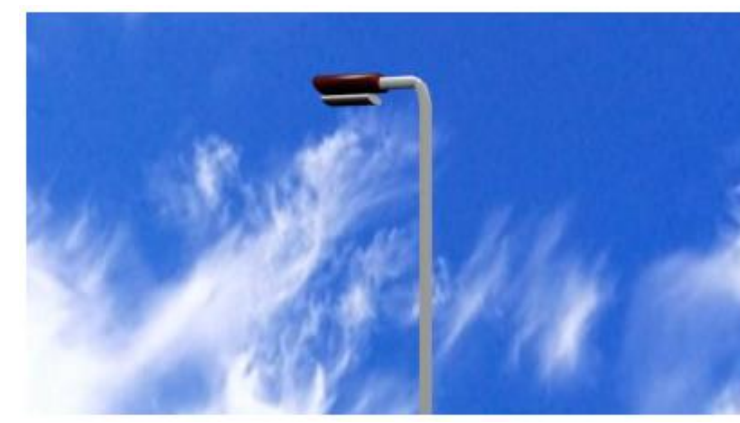

Gambar 7. Lampu Jalan

Air mancur Properti air mancur digunakan pada bundaran jalan. Pembuatan air mancur dilakukan pada aplikasi blender dengan objek dasar cylinder sebagai wadah atau tempat air mancur dan spehere sebagai air mancur. Teknik modelling air mancur 
adalah extrude and scale pada edge dan face. Selain modelling menggunakan aplikasi blender, animasi air mancur juga dilakukan pada aplikasi blender, yaitu dengan cara mengaktifkan physics fluid objek air mancur dengan type domain dengan ketinggian sumbu $\mathrm{z}=1,500$ dan mengaktifkan physics fluid objek wadah dengan type obstacle.

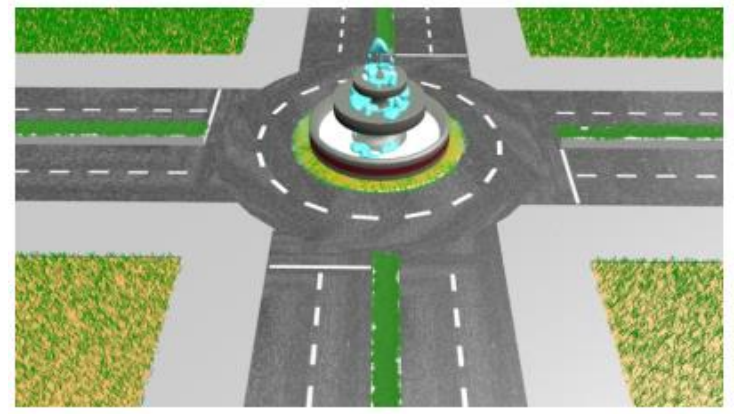

Gambar 8. Air Mancur

Lampu Lalu Lintas. Pembuatan lampu jalan dilakukan pada aplikasi blender dengan objek dasar cylinder dan cube. Dengan teknik modeling extrude and scale. Ukuran dari lampu jalan adalah sumbu $\mathrm{x}=0.800 \mathrm{y}=410.800$ dan $\mathrm{z}=2.000$. Pada bagian ini pembuatan objek harus jelas dan terfokus karena bagian ini merupakan project inti dari video animasi.

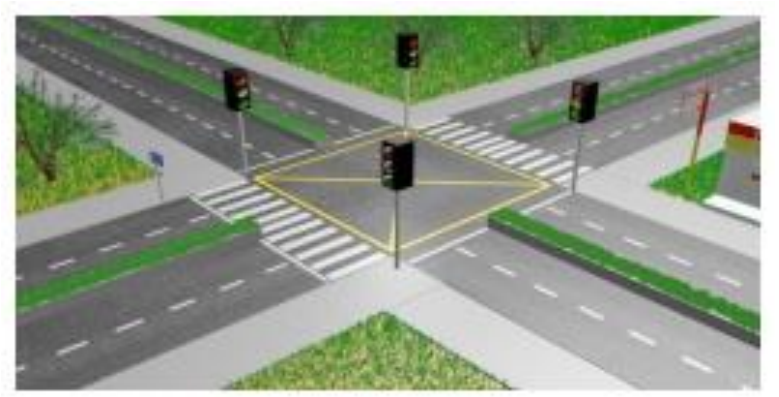

Gambar 9. Lampu Lalu lintas

Mobil. Pembuatan mobil dilakukan pada aplikasi blender dengan objek dasar cube. Teknik modelling yang digunakan yaitu exrude and scale pada edge vertex dan face. Modelling mobil tidak menggunakan texture, hanya menggunakan warna dasar yaitu merah, kuning, hijau dan biru. Karena hanya menggunakan warna dasar, modelling mobil ditambahkan tool smooth agar lebih terlihat mengkilap saat terkena lighting. Untuk kaca mobil menggunakan metode transparance dengan alpha $=0.800$.

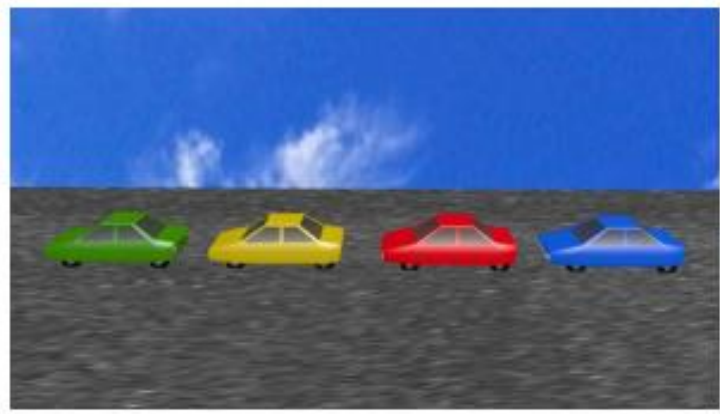

Gambar 10. Properti Mobil

Modelling karakter tokoh utama menggunakan aplikasi makehuman dengan format file collada. Setelah dilakukan modelling pada aplikasi makehuman, karakter tersebut di import ke dalam aplikasi blender. Kemudian pada aplikasi blender karakter ditambahkan rigging agar dapat bergerak atau di atur posisi karakter sesuai yang diinginkan. Import file dari makehuman ke blender. Modelling toko ini dilakukan pada aplikasi blender yaitu dengan objek dasar cube. Teknik modelling yang digunakan yaitu extrude pada face objek cube. Bangunan toko menggunakan 4 texture yang digunakan sebagai nama toko yang diletakkan pada posisi atas pintu toko.

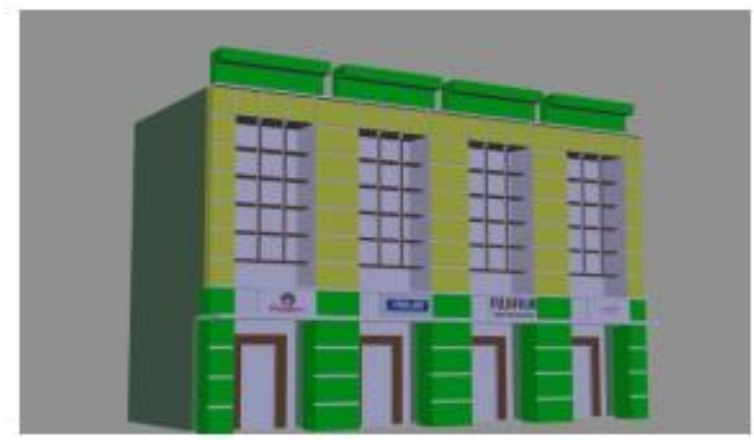

Gambar 11. Bangunan Toko

Modelling karakter tokoh utama menggunakan aplikasi makehuman dengan format file collada. Karakter ini dirancang sebagai pemeran pengguna kendaraan bermotor. Setelah dilakukan modelling pada aplikasi makehuman, karakter tersebut di import ke dalam aplikasi blender. Kemudian pada aplikasi blender karakter ditambahkan rigging agar dapat bergerak atau di atur posisi karakter sesuai yang diinginkan. Aplikasi makehuman ini dapat menggambarkan bentuk tubuh secara detail, antara lain dapat mengatur anatomi badan yaitu tinggi atau pendeknya badan, jenis kelamin, bentuk tubuh, proporsi badan dan lain sebagainya. Selain itu pada makehuman ini dapat mengatur bagian tubuh seperti, kaki, tangan, alis, mata, otot 
dan lain-lain. Kemudian pada makehuman juga dapat membuat aksesoris misalnya baju, kalung, topi. Celana dan lain-lain.

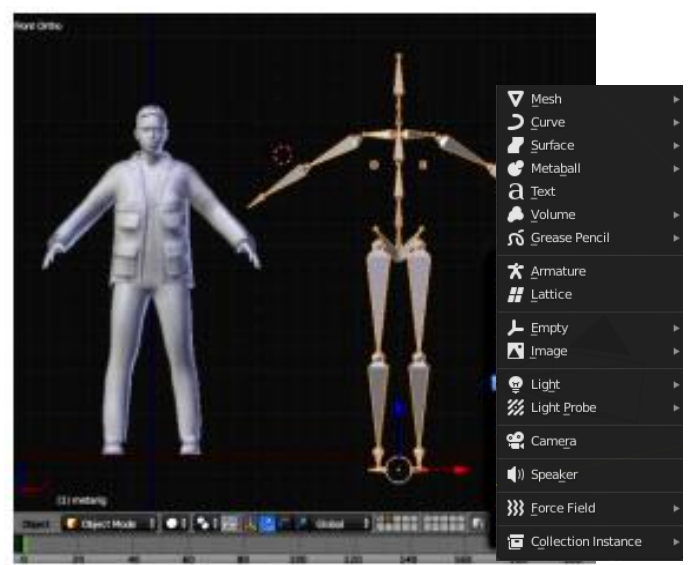

Gambar 12. Pemberian Rigging Pada Karakter

Modelling mini mart dengan objek dasar cube sebagai bangunan, objek dasar cylinder sebagai palang mini mart dan objek dasar plane sebagai papan nama. Teknik modelling yang digunakan yaitu extrude pada face objek.

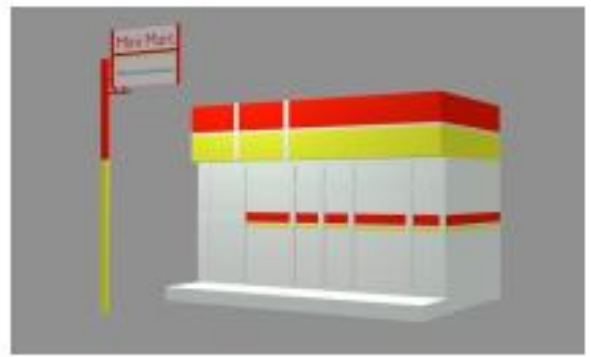

Gambar 13. Bangunan Mini mart

Modelling BANK ABC dilakukan pada aplikasi blender dengan objek dasar cube. Teknik modelling yang digunakan yaitu extrude pada face objek. Bangunan bank menggunakan 1 jenis font yaitu Bubblelovedemo sebagai logo bank. Objek ini adalah objek tambahan dalam pembuatan video animasi 3D.

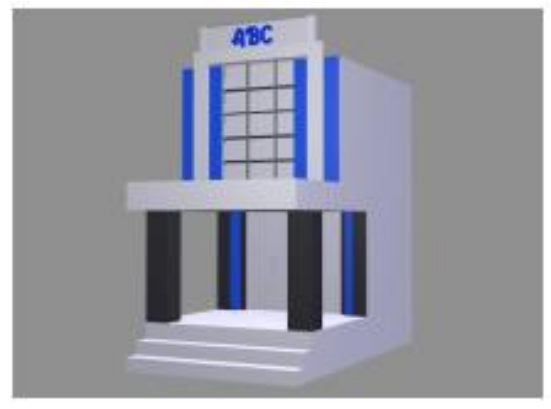

Gambar 14. Bangunan Bank ABC
Modelling rumah dilakukan pada aplikasi blender dengan objek dasar cube sebagai bangunan rumah dan plane sebagai lantai rumah. Teknik modelling yang digunakan yaitu extrude pada face objek. Bangunan rumah menggunakan 4 texture yaitu pada tiang depan, lantai depan, lantai garasi dan atap rumah.

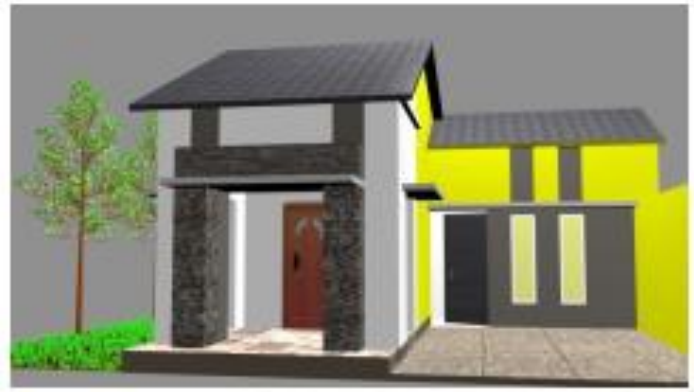

Gambar 15. Rumah

\section{B. Hasil}

Berdasarkan kuesioner yang telah dibuat, penulis membuat jenis pengujian antara lain : uji kelayakan di Polres Sambas yang menggunakan sebagai uji untuk ahli materi dan uji kelayakan untuk masyarakat umum digunakan sebagai uji ahli media. Karakteristik responden diidentifikasi dari empat buah pertanyaan identitas yang tertera pada kuesioner, yaitu nama, umur, jenis kelamin dan jabatan. Karakteristik responden dikelompokkan berdasarkan pekerjaan, umur dan jenis kelamin. Pemberian kuesioner dilakukan secara online yaitu menggunakan google form. Metode pengukuran yang digunakan dalam penelitian ini menggunakan skala likert. Dengan skala likert dapat diketahui tingkat persetujuan dari responden terhadap serangkaian pertanyaan. Tingkat persetujuan yang dimaksud dalam skala likert ini terdiri dari 5 pilihan skala dari Sangat Setuju (SS) hingga Sangat Tidak Setuju (STS).

Pada penelitian ini menghasilkan sebuah video animasi 3 dimensi sosialisasi berkendara dengan berfokus pada jalur simpangan dan bundaran berdurasi 7 menit 47 detik, dengan format file MP4 dan berukuran file 691MB

Berdasarkan kuesioner yang telah dibuat, penulis membuat dua jenis pengujian antara lain: a) Uji kelayakan di Polres Sambas dan b. Uji kelayakan untuk masyarakat umum. Karakteristik responden diidentifikasi dari empat buah pertanyaan identitas yang tertera pada kuesioner, yaitu nama, umur, jenis kelamin dan jabatan. 
Menurut kuesioner yang penulis bagikan, dampak positif video animasi 3 dimensi yang penulis rancang ini memberikan harapan untuk mengurangi tingkat kecelakaan dalam berkendara. Dari video sosialisasi yang penulis rancang ini terdapat $75 \%$ pernyataan sangat setuju isi dari video sosialisasi ini mudah dipahami. Masyarakat dapat dengan mudah menerima informasi yang disampaikan melalui media video animasi 3 dimensi, serta dari pembuatan video sosialisasi ini juga $75 \%$ responden menyatakan pentingnya mengetahui tata cara berkendara di simpangan dan bundaran.

\section{KESIMPULAN}

\section{A. Kesimpulan}

Proses pembuatan animasi 3 dimensi sosialisasi etika berkendara diselesaikan menggunakan metode MDLC sebagai metode pembuatan project. Penelitian ini menghasilkan video animasi 3 dimensi sosialisasi etika berkendara berkendara dengan berfokus pada jalur simpangan dan bundaran berdurasi 7 menit 47 detik, dengan format file MP4 dan berukuran file 691 MB. Informasi yang dikemas dalam bentuk video animasi 3 dimensi ini, membuat masyarakat lebih mudah mempelajari dan memahami tata cara berkendara di simpangan dan bundaran jalan yang sesuai dengan peraturan UU No 22 Tahun 2009 tentang LLAJ guna mengurangi tingkat kecelakaan dalam berkendara.

\section{B. Saran}

Pembuatan animasi 3 dimensi ini diusahakan membagi setiap scene atau adegan cerita karena berpengaruh dalam proses rendering. Untuk pengembangan lebih lanjut mengenai penelitian ini saran dari Bapak Juanda selaku penguji di Polres Sambas ditambahkan UU tata cara menyeberang di lampu merah pada zebra cross dan membuat animasi 3D RBK (Ruang Berhenti Khusus) bagi pengendara. Untuk penelitian selanjutnya bisa ditambahkan peraturan lalu lintas yang lebih banyak. Agar penelitian ini dapat dijadikan referensi bagi mahasiswa dalam mengoptimalkan penggunaan perkembangan teknologi sebagai sarana pemberian edukasi dan informasi khususnya dalam bidang animasi 3 dimensi.

\section{REFERENSI}

Anin. (2020). Sosialisasi dengan Video Animasi. https://animasistudio.com/sosialisasi-denganvideo-animasi/

Cahyadi, M. W., Arthana, I. K. R., \& Pradnyana, I. M. A. (2020). Pengembangan Media Sosialisasi " Disiplin Lalu Lintas "Unit Dikyasa dengan Animasi Motion Graphic dan Konsep Art Animasi " STudi Kasus : Unit Dikyasa Satlantas Polres Buleleng ”. 17(2), 254-264.

Candra. (2017). Manfaat Membuat Animasi Periklanan.

Darmawan, T. M. A., Khairani, S., \& Budiman, A. (2020). Simulasi Lalu Lintas Berkendara Berbasis 3D di Perempatan Jalan. 41-48.

Defar. (2019). Tahap Dasar Pembuatan Animasi $3 D$.

Haryoko, S. (2012). Efektivitas Pemanfaatan Media Audio-Visual sebagai Alternatif Optimalisasi Model Pembelajaran. Jurnal Edukasi, 5.

Hobbs. (2009). Perencanaan dan Teknik Lalu Lintas. Jurnal Mahasiswa Teknik Sipil, 53(9).

Lu, Z., Coster, X., \& de Winter, J. (2017). How Much Time Do Drivers Need to Obtain Situation Awareness? A Laboratory-Based Study of Automated Driving. Applied Ergonomics, 60(2013), 293-304. https://doi.org/10.1016/j.apergo.2016.12.003

Marselia, M., Kusrini, \& Fatta, H. Al. (2017). Perancangan Video Iklan Tiga Dimensi Institut Teknologi Del. Yogyakarta : STMIK AMIKOM.

Moleong, L. J. (2012:330). (2013). Teknik Pengambilan Data. Journal of Chemical Information and Modeling, 53(9).

Nalendra, A. K., Mujiono, M., Akhsani, R., \& Wahyu U, A. S. (2020). Implementasi Algoritma K-Mean dalam Pengelompokkan Data Kecelakaan (Studi Kasus Kabupaten Kediri). VOCATECH: Vocational Education and Technology Journal, 1(2).

Ollie, J., \& Thomas, F. (1981). 12 Dasar Prinsip Animasi.

Priyoatmoko, W. (2017). Pembuatan Video Animasi 2D Penyuluhan Tertib Berlalu. 13(1), 19-25.

Rubil, R., Arini, A., \& Syam, A. S. (2013). Visualisasi 3 Dimensi Tumbuhan Langka di Pusat Konservasi Tumbuhan Kebun Raya Bogor. ComTech: Computer, Mathematics 
and Engineering Applications, 4(2).

https://doi.org/10.21512/comtech.v4i2.2492

Syahfitri, Y. (2011). Teknik Film Animasi dalam

Dunia Komputer. Jurnal SAINTIKOM, 10(3).

Tamin, O. Z. (2008). Perencanaan, Permodelan, \& Rekayasa Transportasi : Teori, Contoh Soal, dan Aplikasi. In Itb.

Widiaty, I., Achdiani, Y., Kuntadi, I., Mubaroq, S. R., \& Zakaria, D. (2018). The 3D Digital Story-Telling Media on Batik Learning in Vocational High Schools. IOP Conference Series: Materials Science and Engineering, 306(1). https://doi.org/10.1088/1757899X/306/1/012062 